\title{
Equity for excellence in academic institutions: a manifesto for
}

\section{change [version 1; peer review: 2 approved]}

\section{Lauren Wedekind ${ }^{1,2^{*}}$, Andrés Noé1* ${ }^{*}$, Jolynne Mokaya (iD) ${ }^{*}$, Cynthia Tamandjou ${ }^{3}$, Melissa Kapulu (104, Andrea Ruecker (D1,5, Evelyn Kestelyn (1D6, Machilu Zimba7, Elham Khatamzas ${ }^{8,9}$, Alice Chi Eziefula10, Claire L. Mackintosh9, Roger Nascimento (1D11, Proochista Ariana11, Denise Best ${ }^{12}$, Edward Gibbs ${ }^{13}$, Susanna Dunachie (D1,13,14, Gina Hadley ${ }^{15,16}$, Hannah Ravenswood7, Bernadette Young (iD)1,14, Charles Kamau4, Kevin Marsh (iD1,17, Helen McShane (D1,14,18, Rob Hale19, Elena McPhilbin1, Pavel V. Ovseiko (i)20, Oxford Equity in Academia consortium, Rebecca Surender ${ }^{21}$, Claire Worland ${ }^{1}$, Lisa J. White (iD)1,5,22, Philippa C. Matthews (iD)1,14,16}

${ }^{1}$ Nuffield Department of Medicine, University of Oxford, Oxford, UK

${ }^{2}$ National Institute of Diabetes and Digestive and Kidney Diseases, National Institutes of Health, Phoenix, Arizona, USA

${ }^{3}$ Division of Health Economics, School of Public Health and Family Medicine, Faculty of Health Sciences, University of Cape Town, Cape Town, South Africa

${ }^{4}$ KEMRI Wellcome Trust, Kilifi, Kenya

${ }^{5}$ Mahidol-Oxford Tropical Medicine Research Unit, Faculty of Tropical Medicine, Mahidol University, Bangkok, Thailand ${ }^{6}$ Oxford University Clinical Research Unit (OUCRU), Hanoi, Vietnam

${ }^{7}$ Equality and Diversity Unit, University of Oxford, Oxford, UK

${ }^{8}$ Department of Medicine III, University Hospital, LMU, Munich, Germany

${ }^{9}$ Regional Infectious Diseases Unit, Western General Hospital, Edinburgh, UK

10University of Sussex, Falmer, Brighton, UK

${ }^{11}$ International Health and Tropical Medicine, Centre for Tropical Medicine and Global Health, Medawar Building, Nuffield Department of Medicine, University of Oxford, Oxford, UK

${ }^{12}$ Oxford University Clinical Academic Graduate School (OUCAGS), John Radcliffe Hospital, Oxford, UK

${ }^{13}$ Department of Tropical Medicine, Nuffield Department of Medicine, University of Oxford, Oxford, UK

${ }^{14}$ Department of Infectious Diseases and Microbiology, Oxford University Hospitals NHS Trust, John Radcliffe Hospital, Oxford, UK

${ }^{15}$ Department of Medicine, Oxford University Hospitals NHS Trust, John Radcliffe Hospital, Oxford, UK

${ }^{16}$ Harris Manchester College, Oxford, UK

${ }^{17}$ Africa Oxford Initiative, Medawar Building, University of Oxford, Oxford, UK

${ }^{18}$ NIHR BRC, Oxford University Hospitals NHS Trust, John Radcliffe Hospital, Oxford, UK

${ }^{19}$ MaynardLeigh Associates, London, UK

${ }^{20}$ Radcliffe Department of Medicine, John Radcliffe Hospital, Oxford, UK

${ }^{21}$ Department of Social Policy, Social Sciences Division, University of Oxford, Oxford, UK

${ }^{22}$ Big Data Institute, University of Oxford, Oxford, UK

* Equal contributors

V1 First published: 07 Jun 2021, 6:142

https://doi.org/10.12688/wellcomeopenres.16861.1

Open Peer Review

Latest published: 07 Jun 2021, 6:142

https://doi.org/10.12688/wellcomeopenres.16861.1
Approval Status 


\author{
Abstract \\ Higher academic institutions in the UK need to drive improvements in \\ equity, diversity, and inclusion (EDI) through sustainable practical \\ interventions. A broad view of inclusivity is based on an intersectional \\ approach that considers race, geographical location, caring \\ responsibilities, disability, neurodiversity, religion, and LGBTQIA+ \\ identities. We describe the establishment of a diverse stakeholder \\ group to develop practical grass-roots recommendations through \\ which improvements can be advanced. We have developed a \\ manifesto for change, comprising six domains through which \\ academic institutions can drive progress through setting short, \\ medium, and long-term priorities. Interventions will yield rewards in \\ recruitment and retention of a diverse talent pool, leading to \\ enhanced impact and output. \\ Keywords \\ Equity, diversity, inclusion, academia, publishing, retention, gender, \\ race, Athena SWAN, Black Lives Matter, Race Equality Charter, STEMM
}

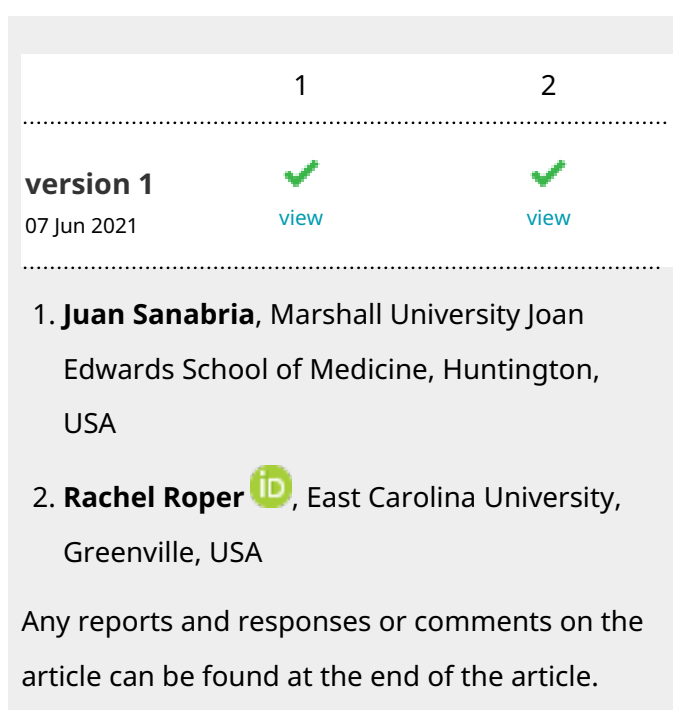

Corresponding author: Philippa C. Matthews (philippa.matthews@ndm.ox.ac.uk)

Author roles: Wedekind L: Conceptualization, Data Curation, Formal Analysis, Writing - Original Draft Preparation; Noé A:

Conceptualization, Data Curation, Formal Analysis, Writing - Original Draft Preparation; Mokaya J: Conceptualization, Data Curation,

Formal Analysis, Writing - Original Draft Preparation; Tamandjou C: Conceptualization, Data Curation, Formal Analysis, Writing -

Original Draft Preparation; Kapulu M: Writing - Review \& Editing; Ruecker A: Writing - Review \& Editing; Kestelyn E: Writing - Review \&

Editing; Zimba M: Writing - Review \& Editing; Khatamzas E: Writing - Review \& Editing; Eziefula AC: Writing - Review \& Editing;

Mackintosh CL: Writing - Review \& Editing; Nascimento R: Writing - Review \& Editing; Ariana P: Writing - Review \& Editing; Best D:

Writing - Review \& Editing; Gibbs E: Writing - Review \& Editing; Dunachie S: Writing - Review \& Editing; Hadley G: Writing - Review \&

Editing; Ravenswood H: Writing - Review \& Editing; Young B: Writing - Review \& Editing; Kamau C: Writing - Review \& Editing; Marsh K:

Writing - Review \& Editing; McShane H: Writing - Review \& Editing; Hale R: Writing - Review \& Editing; McPhilbin E: Writing - Review \&

Editing; Ovseiko PV: Writing - Review \& Editing; Surender R: Writing - Review \& Editing; Worland C: Writing - Review \& Editing; White LJ : Conceptualization, Data Curation, Project Administration, Resources, Supervision, Writing - Original Draft Preparation; Matthews PC: Conceptualization, Data Curation, Project Administration, Resources, Supervision, Writing - Original Draft Preparation

Competing interests: No competing interests were disclosed.

Grant information: This work was not supported by any specific funding. PCM holds a Wellcome Intermediate Fellowship [110110/Z/15/Z].

The funders had no role in study design, data collection and analysis, decision to publish, or preparation of the manuscript.

Copyright: $\odot 2021$ Wedekind L et al. This is an open access article distributed under the terms of the Creative Commons Attribution License, which permits unrestricted use, distribution, and reproduction in any medium, provided the original work is properly cited.

How to cite this article: Wedekind L, Noé A, Mokaya J et al. Equity for excellence in academic institutions: a manifesto for change [version 1; peer review: 2 approved] Wellcome Open Research 2021, 6:142 https://doi.org/10.12688/wellcomeopenres.16861.1

First published: 07 Jun 2021, 6:142 https://doi.org/10.12688/wellcomeopenres.16861.1 


\section{Disclaimer}

The views expressed in this article are those of the authors. Publication in Wellcome Open Research does not imply endorsement by Wellcome.

\section{Introduction}

Academic institutions have a moral imperative to provide an environment in which every individual has the rights and opportunities to participate and develop to their greatest potential $^{1}$. Beyond the case for justice, promoting equity, diversity, and inclusion (EDI), and prioritising accessibility, also stimulates collaboration, output, innovation, and impact ${ }^{2,3}$. A positive spillover of skills and knowledge results from sharing different perspectives ${ }^{4}$, and cultural and cognitive diversity represent different knowledge, external linkages, and social intelligence ${ }^{5}$. Individuals who feel valued and psychologically safe within their working environments contribute more fully ${ }^{6}$, benefiting academic institutions and their partners in healthcare, education, industry, the charity sector, and public engagement, while a diverse workforce can contribute to better governance and ethics and generate output that better represents society ${ }^{7,8}$.

The private sector has increasingly invested in the strong 'business case' for $\mathrm{EDI}^{9,10}$, perhaps because there is a demand for diversity from clients, but also as a result of realising that to benefit from the full talent pool, organisations must recruit and promote members from diverse backgrounds ${ }^{11}$. Conversely, individuals who feel under-valued and under-recognised are more likely to underperform and/or leave their roles ${ }^{12}$. Teams that prioritise EDI build resilience, strengthening their abilities to resolve conflict, address bias, and cope with stress ${ }^{13,14}$.

The measures of excellence for academic institutions are beginning to shift from outdated metrics (e.g., weighted towards academic publication) $)^{15}$ towards more holistic measures of impact $^{16}$. Academic funders increasingly demand delivery of impact through collaborative networks, and expect engagement with the public, research participants, and the private sector ${ }^{17}$. Likewise, research funders have introduced specific EDI mandates ${ }^{18,19}$, while student and staff bodies are demanding reform.

By simply maintaining the status quo, institutions neglecting EDI as a priority risk being overtaken by more diverse competitors, suffering legal, financial, and reputational consequences, losing resources and collaborations, and further minoritising historically excluded groups ${ }^{12}$. Sticking to a 'business as usual' approach for EDI is insufficient. The Athena SWAN Charter, established in the UK in 2005, has delivered some progress in this domain by providing a structured framework to drive improvements in gender equity through action plans, benchmarking, and funding incentives ${ }^{20,21}$. Although it has been criticised for its 'tick-box' approach, the Charter has demonstrably driven awareness and promoted investment, underpinned training, and influenced ractical changes. More recently, Athena
SWAN has undergone review, extending its remit beyond gender to other identities ${ }^{22}$, and recognising the need for intersectional approaches $^{23}$ alongside the establishment of other frameworks such as the Race Equality Charter (REC) ${ }^{24}$ and the Stonewall Workplace Equality Index ${ }^{25}$.

There is now a need to increase the pace of change, while adapting to major global health, political, and climate challenges ${ }^{26}$. We convened a consultative 'Equity in Academia' symposium in September 201927, led through the Nuffield Department of Medicine at the University of Oxford and its international partners, aiming to position EDI as a cornerstone of university activity, making practical changes within faculty, research, communication, leadership, policy, planning, and resource allocation. Our working party included clinicians, academics, and faculty staff at different career stages, including diverse geographical representation facilitated through the Oxford Tropical Network, working in consultation with academic publishers, leaders from our institutional Equity and Diversity networks, and experts in teaching, communication, and human resources. We collected qualitative data before, during, and after the event (available on-line) $)^{28}$.

Since our meeting was convened, the global academic and clinical communities have undergone dramatic changes. The COVID-19 pandemic is associated with wide-ranging influences as a result of population lock-down and repurposing of resources, with the potential for disproportionate negative impact on already minoritised groups ${ }^{29,30}$. Mandates for equity, including Athena SWAN targets, have been set aside. Special efforts will be required to monitor and mitigate wide-reaching effects of this global emergency, and to ensure that progress made towards EDI goals is not eroded. The Black Lives Matter movement ${ }^{31}$ has raised enhanced awareness of ingrained societal inequities based on race, present long before COVID-19, but intersecting with the impact of the pandemic on minoritised and disadvantaged groups $^{32,33}$.

In the body of this article, we summarise practical recommendations, initially developed as an output from our meeting, but subsequently shaped further through consultation with wider EDI stakeholder groups and based on adaptation to the changing landscape.

\section{Recommendations for change}

We present an overarching manifesto comprising six key domains for change, leading to practical recommendations wherever possible. We have considered the timelines over which we anticipate change might be implemented and predicted the resource impact of different targets (Table 1), to help set and deliver focused goals. The aim is to underpin and support strategic change in ways that can be implemented in practice (Figure 1), can be benchmarked, are transparent and become a sustainable investment over time. Our list does not propose to be exhaustive, and individual recommendations should not be addressed in isolation, but rather as part of a developing network 
Table 1. Recommendations for supporting initiatives for equity, diversity, and inclusion (EDI) at academic institutions. We divide our recommendations into six broad domains. Each target is classified according to the likely speed and cost of implementation, to support the development of realistic priorities and timelines. However, we recognise that these attributes vary by time and place, and therefore recommend context-specific evaluation, and frequent reappraisal of goals, backed by relevant local data.

\begin{tabular}{|c|c|c|}
\hline Recommendation & Speed & Cost \\
\hline \multicolumn{3}{|l|}{ Domain one: Improve representation } \\
\hline (i) Invest in visible representation from high level leadership & short & Medium \\
\hline (ii) Improve diversity in university leadership and management roles & Medium & Low \\
\hline (iii) Improve inclusion of historically excluded and under-represented groups across all roles & Medium & Medium \\
\hline (iv) Develop a cohesive organisational structure for equity & Medium & Medium \\
\hline \multicolumn{3}{|l|}{ Domain two: Commit resources } \\
\hline (i) Develop and maintain networks for best practice & Long & High \\
\hline (ii) Commit to equitable funding & short & Medium \\
\hline (iii) Ring-fence funding to work towards targets set by the Race Equality Charter & Medium & Medium \\
\hline (iv) Collect and analyse data & Medium & High \\
\hline \multicolumn{3}{|l|}{ Domain three: Invest in rewards and recognition } \\
\hline (i) Re-focus central institutional reward schemes & Medium & Medium \\
\hline (ii) Offer development opportunities for early career researchers & short & Medium \\
\hline (iii) Create new career opportunities in EDI & Medium & High \\
\hline \multicolumn{3}{|l|}{ Domain four: Tackle bullying and harassment } \\
\hline (i) Tackle challenges and complaints through a consistent framework & short & Medium \\
\hline (ii) Collect and act on leavers' data & short & Medium \\
\hline \multicolumn{3}{|l|}{ Domain five: Build opportunities } \\
\hline (i) Drive improvements in EDI in academic publishing & Long & High \\
\hline (ii) Make the workplace accessible to all & Medium & Medium \\
\hline (iii) Invest in skills, training, and support for EDI initiatives & Medium & Medium \\
\hline (iv) Recalibrate entry requirements & short & Low \\
\hline \multicolumn{3}{|l|}{ Domain six: Support equity through policy } \\
\hline (i) Apply legislation, policy, and expectations universally & Medium & High \\
\hline (ii) Move from policy into practice by setting specific goals and targets & Medium & Medium \\
\hline
\end{tabular}
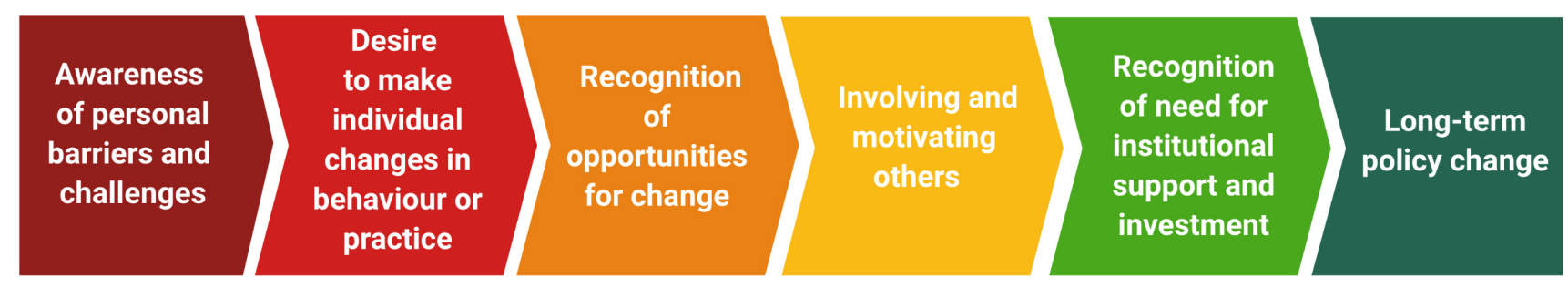

Figure 1. Evolution of events in driving institutional change for improvements in equity and diversity. Summary based on feedback and reflection of participants before, during, and after the Equity in Academia event. Personal contributions and activism are crucial in designing new approaches to promote EDI, but investment from leadership and dialogue with stakeholders at the institutional level are needed to enforce sustainable policy changes that ultimately become embedded in policy. 
of initiatives, with an understanding that particular recommendations need to be adapted or prioritised according to local needs and resources, and tailored to make them context-specific.

\section{Domain one: Improve representation}

(i) Invest in visible representation from high level leadership

Visible leadership in EDI is essential to demonstrate a commitment to delivering practical policy change, and universities are increasingly creating dedicated senior EDI positions. Many of our recommendations require a level of power, influence, or authority within the structure of an institution, requiring representative leadership to deliver and sustain improvements. In addition to designated roles that incorporate an EDI remit, all individuals in leadership positions should be required and incentivised to commit time and resources to improving EDI. However, careful management of targets is required to ensure that outputs cannot be fudged or linked to perverse incentives. Grass-roots change can only be sustained if there is evidence of this personal, practical, and economic investment ${ }^{34}$.

\section{(ii) Improve diversity in leadership and management roles}

Increased effort is required to ensure that panels, committees, and governing boards are as diverse as possible, beyond gender identities alone. To develop an organisational ethos that is intersectional, and to avoid segregation of groups representing different sectors and backgrounds, this diversity must be partnered with an approach that champions inclusion and integration, also offering opportunities to individuals at junior career levels. Contributions to activities that promote EDI should be recognised, rewarded and valued, and responsibilities must be shared to ensure fair distribution of the workload, to avoid a minority of individuals bearing an undue weight of responsibility, especially if these are people who do not represent the existing norms of an institution ${ }^{35}$. Members of well represented groups need to step up on advocacy and allyship ${ }^{36}$, not just leaving the agenda to be promoted by members of minoritised groups.

(iii) Improve inclusion of historically excluded and under-represented groups across all roles

Efforts are required to improve inclusion and intersectionality, with respect to (non-exhaustively) gender, disability, mental or physical illness, neurodiversity, ethnicity, geographical location, and LGBTQIA+ identities. The global South and low/middle income countries (LMIC) remain under-represented among staff and students, and in the academic culture, curriculum, resources and reading lists; research contributions from LMIC settings are often unfairly weighted with disproportionate credit to academic partners in resource-rich environments ${ }^{37}$. Expertise in advertising roles and opportunities is needed to ensure visibility to a wide audience. Blind recruitment may have a role in reducing the impact of (conscious or unconscious) bias in recruitment panels, while mandating diverse short-listing and interview panels would improve equity and inclusivity in decision making.

Institutions can designate dedicated international scholarships and visiting fellowships to enhance mutually beneficial collaboration, with administrative support to provide assistance with travel arrangements. These opportunities can underpin career development and collaboration, alongside inclusion in committees, panels and steering groups, including roles in development and decolonisation of academic curricula, and providing access for minoritised groups to career development and leadership opportunities. Specific de-colonization of the academic sector is particularly central to EDI interventions in countries with traumatic colonial histories.

\section{(iv) Develop a cohesive organisational structure for equity}

Many individual efforts are currently made to improve EDI, but often occur in poorly connected silos. A minimum of one annual meeting at university-wide level is suggested, including representation from international partners, as an opportunity for networking, training, sharing challenges and experiences, convening focus groups, building consensus, and generating practical recommendations. This would also be a valuable opportunity to collect data, invite external speakers and network with other organisations. Such events must be accessible in format, timing, and venue.

\section{Domain two: Commit resources}

(i) Develop and maintain networks for best practice

Investment is required to establish an institution-wide network that builds and maintains personal connections, hosts case studies, catalogues useful references and resources, promotes funding opportunities, and contributes to the organisation of EDI meetings. While we work in a financially challenging climate, budget should be ring-fenced to support and sustain activities, with consideration of how funding is most inclusively deployed and a recognition that investment in this arena leads to longer-term dividends in productivity. Specific incentivisation may be needed within departments to ensure short-term cuts do not curtail progress. Expertise in EDI leadership can thus be grown, alongside the coordination of departmental platforms and resources to support and sustain activity. Investment in new initiatives can improve EDI at an organisational level (local examples are 'Foundation Oxford' and 'Opportunity Oxford') $)^{38}$.

\section{(ii) Commit to equitable funding}

At present, university data show disparities in gender and ethnic representation and pay. Transparent audit and data are required to underpin policies and implement change ${ }^{39}$.

Individuals who take on roles to promote EDI are often already disadvantaged as members of minoritised groups themselves, and typically do so in their own time without compensation, and at a detriment to other personal and professional responsibilities; this phenomenon has been coined the 'minority tax' ${ }^{40}$. University funds are needed to support flexible work arrangements, administrative and research staff, IT, travel, and carers' and hardship funds. EDI activity needs to be formalised in job plans, including participation on committees, or working groups. Academic units should generate written annual commitments to EDI activity, with audit and benchmarking to ensure that these commitments are delivered. 
(iii) Ring-fence funding to work towards targets set by the Race Equality Charter

Goals and targets set by the Athena SWAN Charter for gender equity have taken priority, due to financial incentives for delivery. However, a wider commitment is now required to promote EDI in domains beyond gender. Practical institutional responses to issues raised by the Black Lives Matter campaign are urgently required; for example, Oxford University established the Race Equality Task Force in November 2020, providing a unified approach through which to tackle racial discrimination and drive practical advances in the REC action plan. An active anti-racist stance requires culture change, consistent investment of expertise and resources, and regular scrutiny through benchmarking against targets ${ }^{26}$.

(iv) Collect and analyse data

Data collection and analysis is essential to identify diversity gaps and focus resources appropriately to tackle the areas of greatest need ${ }^{41,42}$, which may vary between organisations and even between departments in a single institution. Undertaking this in a meaningful way requires the allocation of time, resources, and skills. Having identified and agreed specific EDI targets, progress should be tracked through repeat data collection and audit, to affirm positive outcomes and to identify areas where further effort is required. Regular public reporting of such data is good practice and an incentive to build on progress ${ }^{43}$. A challenge for data analysis is the trade-off between the value of disaggregated data in order to develop a high-resolution picture, versus the risk of raising privacy issues. Using external agencies to analyse data and make recommendations is a potential way to address this concern, removing the risk of specific individuals being identified.

\section{Domain three: Invest in rewards and recognition \\ (i) Re-focus central institutional reward schemes}

Many universities offer merit awards and have programmes for recognition of distinction, typically focusing on publication and funding as metrics. However, the impact that can be delivered through teaching, leadership, and EDI roles should be recognised and rewarded as equally important domains. Although equity awards are currently offered, such opportunities need to be expanded, advertised, and championed, with consideration of appropriate metrics or key performance indicators. New 'ambassador' roles could support individuals who deliver impact in improving EDI. Selection panels for recognition of distinction must themselves represent and champion diversity.

(ii) Offer development opportunities for early career researchers Existing 'honorary visiting research fellowship' and 'visiting professorship' schemes recognise mid/senior career stages, enhancing geographical diversity, and providing career opportunities. We propose the addition of a similar title for early-career researchers; for example, 'junior visiting research fellowships' with college or departmental affiliations could be introduced, together with a parallel series of awards that support projects with a specific EDI focus.

\section{(iii) Create new career opportunities in EDI}

Academic institutions should consider the creation of more specific EDI posts, as well as creating flexibility in compensated positions to formally protect time for EDI work in parallel with other roles, with these opportunities advertised alongside other posts. This would require the provision of extra resources to allow appointed applicants to undertake a formal 'equity brief'.

\section{Domain four: Tackle bullying and harassment}

(i) Tackle challenges and complaints through a consistent framework

The individual complaints procedure is well documented in most institutions, with formal frameworks through which concerns are addressed. Unfortunately, it remains the case that culture and job security challenges often inhibit people from coming forward. One way to protect individuals is to collate any complaints which may indicate potentially deeper systemic problems to be strategically addressed at an institutional level, rather than as a series of unrelated issues. Responses to complaints should be planned directly with stakeholders (including issues that may be raised outside the formal complaints process). Serious concerns should be handled at a departmental or organisational level to liberate the individual complainant from the onus of personal responsibility or fears of individual repercussions. Dedicated mechanisms can be implemented to collate concerns that should be dealt with collectively, such as racism or harassment. Complaints should be dealt with efficiently to demonstrate a 'zero tolerance' policy, strict adherence to the law, and reflecting institutional and funders' policies ${ }^{39}$.

\section{(ii) Collect and act on leavers' data}

Improved transparency and enhanced sensitivity are required in the collection and analysis of data at 'exit interviews' to identify hostile environments, and to spotlight micro- and macro-aggression that cause academic staff and faculty members to leave their positions ${ }^{44}$. This opportunity for learning is a well recognised process but in practice is not consistently undertaken, or acted upon. More efforts to understand the optimum ways to collect and learn from such data are needed, and to determine the value of the process in order to justify ongoing investment.

\section{Domain five: Build opportunities}

(i) Drive improvements in EDI in academic publishing

More data are needed to understand, highlight, and tackle equity gaps in academic publishing ${ }^{45,46}$, including editorial membership and peer review ${ }^{43,47}$. By investing in acquiring, analysing, and publishing its own data regarding EDI in authorship ${ }^{15}$, academic institutes can inform local improvements, and leverage publishers to demonstrate equity and diversity among authors, 
reviewers, and editors. Universities should lobby for provision of training in publishing and peer review, making this relevant and accessible to researchers in LMICs with costs shared by publishers. Academic trainees, faculty, administrators, and support staff need opportunities and incentives to collaborate, research and publish on EDI topics to share experiences and influence institutional improvements. Action is required to ensure that subjects and participants of research are represented equitably (e.g., advocating for improved diversity of representation of study subjects by age/sex/ethnicity $)^{48}$.

\section{(ii) Make the workplace accessible to all}

Greater resource and staff allocation are required to modify and improve workplace, living and conference environments to cater to diverse needs of the workforce, including such considerations as step-free access, accessible public transport or car parking, hearing loops, sign language interpretation, and captioning. Childcare, parental leave, and flexible working hours must be championed to support all those with caring responsibilities, including - but not exclusive to - working parents and carers.

(iii) Invest in skills, training, and support for EDI initiatives

Greater commitment is required to provide programmes that build and nurture transferable skills, such as communication, negotiation, leadership, advocacy, self-confidence, and empathy, breaking down stereotypes, and (implicit and explicit) bias that may inhibit minoritised communities. Resource is needed to provide high quality training that is available both on-line and face-to-face, and should be mandated for those in teaching, mentorship, leadership, or recruitment roles. Prudent investment recognises the merits of intersectional approaches and draws on successful initiatives in other sectors (e.g., industry, healthcare, military, and the media). Mentorship and sponsorship schemes that are supported through university investment need to be flexible and adaptive to the needs, interests, and challenges of the mentee, and can be used to develop and maintain connections between teams and departments. A diverse view of relevant and valuable skills is needed, to broaden the nature of training that is provided and to dismantle traditional views of leadership which perpetuate the status quo.

\section{(iv) Recalibrate entry requirements}

Admissions to posts across all institutional levels (e.g., internships, studentships, and professorships) should be holistically reviewed, accounting for barriers that the applicant may have had to overcome ${ }^{49}$, adjusting pro-rata for career breaks, and considering the potential that they show beyond publications, impact factors, grade-point averages and standardised test scores.

\section{Domain six: Support equity through policy}

(i) Apply legislation, policy, and expectations universally

Universities should uphold and publicise universal mandates to deliver on EDI goals, such that expectations are explicitly shared with affiliated institutions, collaborators, and partners in other domains, such as industry and the charitable sector.
Infrastructure and resources are needed to support aspirations of teams who can exemplify excellence and deliver output that sustainably improves institutional EDI, such as actively prioritising targets set by the Racial Equality Charter.

(ii) Move from policy into practice by setting specific goals and targets

Following review and agreement within the appropriate domain, mandates for changes involving domains one to five above should be enshrined in policy, with active monitoring and sanctions applicable if not delivered.

\section{Discussion}

Based on output from an international multi-disciplinary symposium, wide consultation with relevant stakeholders and experts, and review of a range of published sources, we have developed a manifesto of recommendations for enhancing EDI at academic institutions. While there is a diverse literature in this field, it remains the case that consistent, evidence-driven approaches to enhancing EDI have not been widely adopted across academia. We have therefore set out to unify expertise and experience, in order to collate recommendations into an accessible format to help inform EDI interventions in complex university environments, with the aim of providing leverage for meaningful and sustainable change.

Beyond the moral imperative, prioritising EDI through the 'innovation economy' can deliver returns on investment, through diversifying research and teaching, accessing a larger pool of talent, and increasing the likelihood of winning competitive funding. The case for reputation recognises that there are inherent risks for institutions that fail to keep pace. While the reasons for prioritising EDI are well recognised, there is a gap between 'knowing' and 'doing' within organisations', and it has been too easy to adopt a passive approach rather than actively challenging inequities, recently highlighted by calls for anti-racism in science ${ }^{43}$. To close these gaps, resources must be sustainably invested in an organisation-wide EDI agenda with high-level institutional support. We recognise that different organisations, institutions, and disciplines have their own complex systems and cultures, which need to be accounted for when planning change, such that interventions have the maximum chance of success in that specific context. An example is 'women in chemistry' ${ }^{50}$, through which challenges in a particular arena are both highlighted and addressed.

Universal EDI policies and standards should be developed upon consultation with wide stakeholder groups, and transparently scrutinised, so that expectations are consistent across departments, divisions, and institutions, irrespective of geography. Reliance on self-selected volunteers (typically from minoritised groups) to drive advocacy, collect data, manage projects, and implement changes can no longer be accepted ${ }^{51}$.

EDI policy changes and enforcement are complex and far-reaching. Academic institutions work with limited resources that must be shared across domains, with potentially competing 
risks and benefits. Some interventions and policies designed to support EDI carry the risks of unintended consequences; without stakeholder engagement and a receptive environment, a 'backlash' effect can paradoxically cause the most harm to the groups that a policy set out to support. Likewise, we must recognise and avoid the 'deficit model' where solutions are aimed at changing the individual instead of addressing a problem in the system, culture, or institution ${ }^{24}$.

Data collection is essential to focus activities to promote EDI, but requires expertise and resources, and can be difficult in the complex multi-dimensional space of a university, in which the impact of an intervention may not be easy to measure. Institutions must avoid imposing an additional layer of pressure and demands on minoritised and historically excluded groups, for whom opportunities are sometimes offered alongside an unrealistic expectation that their involvement will inherently and immediately deliver improvements. True commitment to EDI must be managed with shared responsibility and realistic timeline expectations, being mindful of potential challenges and considering how to measure success of a programme or intervention.

The academic model in which individual achievement is recognised and rewarded only through metrics of publication and grant income is slowly being diversified. However, further incentives for change will be crucial to dismantle existing this outdated approach to appraisal, for example recognising distinction in fields that include leadership and citizenship, teaching, collaborations, EDI commitments and public engagement.

Complete strategic change is required to put EDI at the heart of policy for higher education institutions. The COVID pandemic has taught us that academic institutions can be agile in making changes at speed when deemed essential to sustain activity and productivity; if we can capitalise on the same innovation and investment for EDI interventions, then there is potential for huge progress ${ }^{52}$. Interventions need to be resourced, developed, and delivered with consideration of positive impact, while offsetting potential risks and costs, scrutinised through benchmarking and feedback, and delivered with transparency and sustainability.

\section{Data availability}

Underlying data

Figshare: Equity in Academia: Supporting Material collected through a workshop at Oxford University (September 2019). https:// doi.org/10.6084/m9.figshare.13849964.v2 ${ }^{28}$.

The project contains the following underlying data:

- EIA supplementary data.pdf (qualitative information collected from meeting delegates, before, during and after the workshop)

- Equity in Academia.jpg 1-14 (visual representations of the day's events, summarising themes and discussions. Artwork produced by Alex Hughes at Drawnalism (https://drawnalism.com/), posted with permission.)

\section{Extended data}

Figshare: Equity in Academia: Supporting Material collected through a workshop at Oxford University (September 2019). https://doi.org/10.6084/m9.figshare.13849964.v228.

This project contains the following extended data:

- s16861-V1-2-Suppl_Table_1_210421_Equity_in_ Academia_-_consortium_authorship_list.xlx (Consortium author list and affiliations). All the individuals named in the consortium have agreed to have their names and affiliations published and available in a publicly accessible repository.

Data are available under the terms of the Creative Commons Attribution 4.0 International license (CC-BY 4.0).

\section{Acknowledgements}

The Oxford Equity in Academia meeting in 2019 received funding support from The Nuffield Department of Medicine and Oxford Tropical Network (OTN) and was hosted by St Catherine's College, Oxford. We are grateful for the support of the Lancet Editorial Team, in planning and delivery of the Equity in Academia meeting. Thanks to Ainura Moldokmatova for administrative help in submitting the manuscript.

The full list of Oxford Equity in Academia consortium members can be found in the Extended data.
1. Osborn M, Rees T, Bosch M, et al: Science Policies in the European Union: Promoting excellence through mainstreaming gender equality. 2000. Reference Source

2. Swartz TH, Palermo AGS, Masur SK, et al.: The Science and Value of Diversity: Closing the Gaps in Our Understanding of Inclusion and Diversity. I Infect Dis. 2019; 220(220 Suppl 2): S33-41.

PubMed Abstract | Publisher Full Text | Free Full Text

3. Roper RL: Does Gender Bias Still Affect Women in Science? Microbiol Mol BiO/ Rev. 2019; 83(3): e00018-19.

PubMed Abstract | Publisher Full Text | Free Full Text
4. Kemeny T, Cooke A: Spillovers from immigrant diversity in cities. J Econ Geogr. 2018; 18(1): 213-45. Publisher Full Text

5. Chamorro-Premuzic T: The Case For Boosting Cognitive Diversity In Organizations. Forbes Magazine. 2018; (accessed March 9, 2020). Reference Source

6. Kmietowicz Z, Ladher N, Rao M, et al.: Ethnic minority staff and patients: a health service failure. BMJ. 2019; 365: I2226. PubMed Abstract | Publisher Full Text

7. West MA, Hwang S, Maier RV, et al.: Ensuring Equity, Diversity, and Inclusion 
in Academic Surgery: An American Surgical Association White Paper. Ann Surg. 2018; 268(3): 403-7.

PubMed Abstract | Publisher Full Text

8. Science benefits from diversity. Nature. 2018; 558(7708): 5 PubMed Abstract | Publisher Full Text

9. Hampton-Alexander Review: FTSE Women Leaders. Improving gender balance in FTSE Leadership. 2018. Reference Source

10. Nathan M: Ethnic diversity and business performance: Which firms? Which cities? Environ Plan A. 2016; 48(12): 2462-83. Publisher Full Text

11. The Allocation of Talent and U.S. Economic Growth. The Econometric Society. (accessed March 7, 2020)

Reference Source

12. Thomas R: The real reason women quit tech (and how to address it). 2016. Reference Source

13. Justice, equity, diversity, inclusion, and resilience. (accessed April 21, 2021). Reference Source

14. Dhatt R, Theobald S, Buzuzi S, et al.: The role of women's leadership and gender equity in leadership and health system strengthening. Glob Health Epidemiol Genom. 2017; 2: e8.

PubMed Abstract | Publisher Full Text | Free Full Text

15. Matthews PC: Fairness in scientific publishing [version 2; peer review: 3 approved]. F1000Res. 2016; 5: 2816.

PubMed Abstract | Publisher Full Text | Free Full Text

16. Research Excellence Framework. REF 2019 Guidance on Submissions; (accessed December 2019). Reference Source

17. Global Challenges Research Fund (GCRF): Strategic Advisory Group. Criteria for GCRF Funding; accessed December 2019. Reference Source

18. Irish Funding Bodies to Require Athena SWAN Gender Equality Accreditation for Higher Education Institutions to be Eligible for Research Funding. (accessed Oct 19, 2020). Reference Source

19. Else $\mathrm{H}$ : Report harassment or risk losing funding, says top UK science funder Nature. 2018: 557(7704): 149 PubMed Abstract | Publisher Full Text

20. Athena SWAN Charter Equality Challenge Unit. (accessed Jan 8, 2020). Reference Source

21. Ovseiko PV, Chapple A, Edmunds LD, et al.: Advancing gender equality through the Athena SWAN Charter for Women in Science: an exploratory study of women's and men's perceptions. Health Res Policy Syst. 2017; 15(1):

PubMed Abstract | Publisher Full Text | Free Full Text

22. Ovseiko PV, Pololi LH, Edmunds LD, et al.: Creating a more supportive and inclusive university culture: a mixed-methods interdisciplinary comparative analysis of medical and social sciences at the University of Oxford. Interdiscip Sci Rev. 2019; 44: 166-91. Publisher Full Text

23. Steinmetz K: She Coined the Term 'Intersectionality' Over $\mathbf{3 0}$ Years Ago. Here's What It Means to Her Today. Time. 2020; published online Feb 20. (accessed April 21, 2021).

Reference Source

24. Race Equality Charter. (accessed Feb 5, 2021).

Reference Source

25. Stonewall. (accessed Feb 10, 2021).

Reference Source

26. Weale S: Disillusioned black Oxford students unwilling to help attract others. The Guardian. 2020; published online June 12. (accessed Feb 10, 2021). Reference Source

27. Ruecker A, Mokaya J, Noé A, et al.: Equity in Academia. figshare. 2019 Publisher Full Text

28. Matthews $\mathrm{P}$, Mokaya J, Noé A, et al.: Equity in Academia: Supporting Materia collected through a workshop at Oxford University (September 2019). 2021

http://www.doi.org/10.6084/m9.figshare.13849964.v2

29. Woitowich NC, Jain S, Arora VM, et al: COVID-19 Threatens Progress Toward Gender Equity Within Academic Medicine. Acad Med. 2021; 96(6): 813-816. PubMed Abstract | Publisher Full Text | Free Full Text

30. Malisch JL, Harris BN, Sherrer SM, et al.: Opinion: In the wake of COVID-19, academia needs new solutions to ensure gender equity. Proc Natl Acad SCi USA. 2020: 117(27): 15378-81.

PubMed Abstract | Publisher Full Text | Free Full Text
31. Black Lives Matter https://blacklivesmatter.com. (accessed Feb 7, 2021).

32. Sherman BW, Kelly RK, Payne-Foster P: Integrating Workforce Health Into Employer Diversity, Equity and Inclusion Efforts. Am J Health Promot. 2021; 35(5): 609-612.

PubMed Abstract | Publisher Full Text

33. Crooks N, Donenberg G, Matthews A: Ethics of research at the intersection of COVID-19 and black lives matter: a call to action. J Med Ethics. 2021; medethics-2020-107054.

PubMed Abstract | Publisher Full Text | Free Full Text

34. Boyce AS: Lessons learned using a values-engaged approach to attend to culture, diversity, and equity in a STEM program evaluation. Eval Program Plann. 2017; 64: 33-43.

PubMed Abstract | Publisher Full Text

35. Ahmed S: Rocking the Boat: Women of Colour as Diversity Workers. In: Arday J, Mirza HS, eds. Dismantling Race in Higher Education: Racism, Whiteness and Decolonising the Academy. Cham: Springer International Publishing, 2018; 331-48.

Publisher Full Text

36. Atcheson S: Allyship - The Key To Unlocking The Power Of Diversity. Forbes Magazine. 2018; (accessed March 9, 2020) Reference Source

37. Are research links with the developing world still a one-way street? 2020 published online Jan 9. (accessed April 21, 2021). Reference Source

38. Two new Oxford initiatives to help students from under-represented backgrounds. University of Oxford. (accessed March 11, 2020). Reference Source

39. Raj A, Kumra T, Darmstadt GL, et al.: Achieving Gender and Social Equality: More Than Gender Parity Is Needed. Acad Med. 2019: 94(11): 1658-64. PubMed Abstract | Publisher Full Text

40. Carson TL, Aguilera A, Brown SD, et al.: A Seat at the Table: Strategic Engagement in Service Activities for Early-Career Faculty From Underrepresented Groups in the Academy. Acad Med. 2019; 94(8): 1089-93. PubMed Abstract | Publisher Full Text | Free Full Text

41. Elsevier: The Researcher Journey Through a Gender Lens. 2020. Reference Source

42. London School of Economics: Why Gender Bias Still Occurs And What We Can Do About It. Forbes Magazine. 2019; published online July 5. (accessed March 9, 2020)

Reference Source

43. Mehta $D$, Bediako $Y$, de Winde $C M$, et al.: Ways to increase equity, diversity and inclusion. Elife. 2020; 9: e60438.

PubMed Abstract | Publisher Full Text | Free Full Text

44. Underrepresented faculty members share the real reasons they have left various academic institutions (opinion). Inside Higher Ed. (accessed March 9 2020). Reference Source

45. JEM Editorial Team: Gender disparity in scientific publishing: What can we do? J Exp Med. 2020; 217(3): e20200291. PubMed Abstract | Publisher Full Text | Free Full Text

46. Nafade V, Sen P, Pai M: Global health journals need to address equity, diversity and inclusion. BMJ Glob Health. 2019; 4(5): e002018. PubMed Abstract | Publisher Full Text | Free Full Text

47. Murray D, Siler K, Larivière V, et al:: Author-Reviewer Homophily in Peer Review, bioRxiv, 2019; 400515. Publisher Full Text

48. Tannenbaum C, Ellis RP, Eyssel F, et al:: Sex and gender analysis improves science and engineering Nature. 2019; 575(7781): 137-46. PubMed Abstract | Publisher Full Text

49. Vale C, Atweh B, Averill R, et al.: Equity, Social Justice and Ethics in Mathematics Education. In: Makar K, Dole S, Visnovska J, Goos M, Bennison A, Fry K, eds. Research in Mathematics Education in Australasia 2012-2015. Singapore: Springer Singapore, 2016; 97-118. Publisher Full Text

50. Kundu S: Women in chemistry. Nat Chem. 2019; 11(7): 603-4. PubMed Abstract | Publisher Full Text

51. Blackstock U, Yamey G, McGowan S, et al:: Why black doctors like me are eaving academic medicine - STAT. STAT. 2020; published online Jan 16. (accessed March 9, 2020). Reference Source

52. Montgomery BL: Make equity essential to expedite change in academia. Nat Microbiol. 2021; 6(1): 7-8.

PubMed Abstract | Publisher Full Text 


\section{Open Peer Review}

\section{Current Peer Review Status:}

\section{Version 1}

Reviewer Report 05 August 2021

https://doi.org/10.21956/wellcomeopenres.18599.r44872

(C) 2021 Roper R. This is an open access peer review report distributed under the terms of the Creative Commons Attribution License, which permits unrestricted use, distribution, and reproduction in any medium, provided the original work is properly cited.

\section{Rachel Roper}

Department of Microbiology and Immunology, Brody School of Medicine, East Carolina University, Greenville, NC, USA

Equity for excellence in academic institutions: a manifesto for change is a valuable article that proposes many useful steps to improve equity, diversity, and inclusion (EDI, or DEI in some geographic regions, e.g. the US). The authors do an excellent job in describing or reminding readers of the many and various ways that diversity is important and beneficial to everyone. Figure 1 shows an image of required steps for improvements. I particularly like step 1, the "Awareness of personal barriers and challenges". Those who do not believe there is any problem with equity and diversity often suggest that women, minority, or other historically underrepresented groups (URGs) do not have the aptitude or desire to work in such professions, do not work hard enough, or perhaps want to be homemakers rather than be in the workforce. This is why it is crucial to publicize and educate faculty on the many well-designed studies that demonstrate statistically significant gender and racial bias in academia today (reviewed in reference 3, Roper RL: Does Gender Bias Still Affect Women in Science? Microbiol Mol Biol Rev. 2019; 83(3): e00018-19, and Eaton et al. How Gender and Race Stereotypes Impact the Advancement of Scholars in STEM: Professors' Biased Evaluations of Physics and Biology PostDoctoral Candidates, June 2019 Sex Roles. $)^{1}$ These studies show that it is the faculty and administrators today who are controlling the success and careers of others, and it is we who can effect change.

The authors make an excellent recommendation to have a minimum of one annual meeting at university-wide level to address EDI efforts, encourage crosstalk between different units and harmonize efforts. This will have the additional benefit of raising awareness and reminding all of campus about EDI. At such a meeting, updates could be given on the diversity data of the institution and comparisons made to national or international norms of faculty and student composition. For example, in the USA, we have the National Faculty Distribution Survey that Oklahoma State University administers every two years covering approximately 80 U.S. institutions and 100,000 faculty, giving data on gender and minority faculty. Universities can compare their departments to national averages to see if there are particular departments that are far below the norms and which may need particular attention from administration. The authors correctly point 
out the difficulty of presenting data on small sets such as departments, where privacy issues can be a concern. In the US for instance, a person's gender is protected data, so often only data sets larger than 5 can be publicly discussed or presented. Larger aggregates of data can be presented. However, acquiring the data is a fundamental first step. We must know where we are in order to measure progress.

The article underscores that those who promote EDI "are often already disadvantaged as members of minoritised groups themselves, and typically do so in their own time without compensation, and at a detriment to other personal and professional responsibilities; this phenomenon has been coined the 'minority tax"'. Since this work is much needed, it is an imperative for universities to officially recognize and reward such time and effort. Many faculty are judged based on three categories; research (publication and grants), teaching and service. It may be wise to add a fourth official category to impress its importance since it seems to be often overlooked and undervalued. Research indicates that faculty may be the most effective at delivering EDI training to faculty since they share the same community, culture and language (Smith, et al. 2015 Now Hiring! Empirically Testing a Three-Step Intervention to Increase Faculty Gender Diversity in STEM BioScience, and Devine et al. 2017. A Gender Bias Habit-Breaking Intervention Led to Increased Hiring of Female Faculty in STEMM Departments.J Exp Soc Psychol.), ${ }^{2}$ , 3 so recognizing and rewarding faculty for this work is crucial.

The authors suggest that blind (anonymous) recruitment or evaluation may have a role to avoid bias in selection. There is support for this in a recent study on applications for time on the Hubble Space telescope. When applications were made anonymous the success rate for women increased dramatically and for the first time was higher than for men (Dual-anonymization Yields Promising Results for Reducing Gender Bias: A Naturalistic Field Experiment of Applications for Hubble Space Telescope Time, Johnson and Kirk 2020. The Astronomical Society of the Pacific). ${ }^{4}$ However, anonymizing applications cannot make up for poverty, poor early circumstances in educational opportunities, or accumulated bias over the applicant's lifetime. For example, in the US, American schools have become segregated by race again, and predominantly white school districts have collectively $\$ 23$ billion more per year indicating that racial/ethnic minority groups receive fewer educational opportunities in lower quality schools (https://www.npr.org/sections/live-updatesprotests-for-racial-justice/2020/07/07/888469809/how-funding-model-preserves-racialsegregation-in-public-schools). This then, in turn, may result in reduced success in college and graduate school. The US National Science Foundation reports that only $8.8 \%$ of science and engineering PhD's were awarded to minority people in 2015 (

https://www.nsf.gov/statistics/2017/nsf17306/report/who-earns-a-us-doctorate/race-andethnicity.cfm). Since having a PhD is normally a prerequisite for a faculty position, this makes hiring a representative proportion of diverse faculty from historically underrepresented groups (URG) a near impossible challenge. Search and admissions committees must evaluate the circumstance of the applicants and not just obvious accomplishments that are much easier for a person with privilege to obtain. Faculty should also encourage individuals from historically underrepresented groups to go to graduate school for advanced degrees, and funding should be available to support them.

The article points out the need for EDI to be enshrined in policy. There are many ways that this can be accomplished. It can be written into job descriptions for department chairs and graduate student directors, that they have a responsibility to create and ensure an atmosphere supportive of diversity, equity and inclusion. Policies should require equity in space, resources and the amount of start up funds faculty members receive. Universities can institute multiple levels of promotion and/or tenure review so that if a department/unit votes against a person, it can be 
reviewed by an upper level, perhaps school-wide committee. Since EDI is often simply forgotten in normal department functioning, it can be written into unit/department governance codes and procedures to remind everyone to think about and pay attention to diversity issues in: evaluation of how faculty members treat diverse students, in any analysis of salary increases, for service work in DEI, and the extra mentoring work that minority/historically underrepresented faculty end up doing helping URG students and supporting them to enter what may be historically white and male dominated fields. Raising awareness of bias, reminding faculty of EDI during normal operations, monitoring data, and giving credit for EDI work will have important benefits in improving EDI at universities.

\section{References}

1. Eaton A, Saunders J, Jacobson R, West K: How Gender and Race Stereotypes Impact the Advancement of Scholars in STEM: Professors' Biased Evaluations of Physics and Biology PostDoctoral Candidates. Sex Roles. 2020; 82 (3-4): 127-141 Publisher Full Text

2. Smith JL, Handley IM, Zale AV, Rushing S, et al.: Now Hiring! Empirically Testing a Three-Step Intervention to Increase Faculty Gender Diversity in STEM.Bioscience. 2015; 65 (11): 1084-1087 PubMed Abstract | Publisher Full Text

3. Devine PG, Forscher PS, Cox WTL, Kaatz A, et al.: A Gender Bias Habit-Breaking Intervention Led to Increased Hiring of Female Faculty in STEMM Departments.J Exp Soc Psychol. 2017; 73: 211-215 PubMed Abstract | Publisher Full Text

4. Johnson S, Kirk J: Dual-anonymization Yields Promising Results for Reducing Gender Bias: A Naturalistic Field Experiment of Applications forHubble Space Telescope Time. Publications of the Astronomical Society of the Pacific. 2020; 132 (1009). Publisher Full Text

Is the rationale for the Open Letter provided in sufficient detail? Yes

Does the article adequately reference differing views and opinions? Yes

Are all factual statements correct, and are statements and arguments made adequately supported by citations?

Yes

Is the Open Letter written in accessible language?

Yes

Where applicable, are recommendations and next steps explained clearly for others to follow?

Yes

Competing Interests: No competing interests were disclosed.

Reviewer Expertise: Gender bias in STEMM, poxvirology, coronaviruses

I confirm that I have read this submission and believe that I have an appropriate level of expertise to confirm that it is of an acceptable scientific standard. 
Reviewer Report 05 July 2021

https://doi.org/10.21956/wellcomeopenres.18599.r44330

(c) 2021 Sanabria J. This is an open access peer review report distributed under the terms of the Creative Commons Attribution License, which permits unrestricted use, distribution, and reproduction in any medium, provided the original work is properly cited.

\section{Juan Sanabria}

Department of Surgery, Marshall University Joan Edwards School of Medicine, Huntington, WV, USA

Authors present elegantly a manifesto of ideas to increase and maintain diversity and equity in academic and perhaps, non-academic health systems and organizations.

Although I agree enterally with the content and aims, it will require a major shift of culture for each Institution/Organization. In my experience, this is the most difficult change. It takes time, resources, persistence and the buy of the goals by all stakeholders.

It would help a timeframe guidance for each goal, the slow-downs and set backs and a practical guidance to overcome the expected fences at different levels.

Is the rationale for the Open Letter provided in sufficient detail?

Yes

Does the article adequately reference differing views and opinions?

Yes

Are all factual statements correct, and are statements and arguments made adequately supported by citations?

Yes

Is the Open Letter written in accessible language?

Yes

Where applicable, are recommendations and next steps explained clearly for others to follow?

Yes

Competing Interests: No competing interests were disclosed.

Reviewer Expertise: Basic and translational cancer biology and metabolism

I confirm that I have read this submission and believe that I have an appropriate level of expertise to confirm that it is of an acceptable scientific standard. 